\title{
Analisa Kualitas Sinar-X Pada Variasi Ketebalan Filter Aluminium Terhadap Dosis Efektif
}

\author{
Ella Nurlela $^{1}$, Purwantiningsih ${ }^{1}$, Budi Santoso ${ }^{1}$ \\ ${ }^{1}$ Program Studi Fisika, Universitas Nasional, Jalan Sawo Manila, Pejaten, Pasar Minggu \\ Jakarta Selatan 12520 \\ Korespondensi : purwanti.ningsih85@yahoo.co.id
}

\begin{abstract}
ABSTRAK. Telah dilakukan pengukuran X-Ray Machine Shimadzu General Multi Purpos untuk mengetahui kualitas sinar-x pada variasi penggunaan filter aluminium terhadap dosis efektif dengan menggunakan lembaran Alumunium yang mempunyai ketebalan bervariasi mulai dari variasi tanpa filter tambahan, dengan filter $0,5 \mathrm{~mm} \mathrm{Al}, 1 \mathrm{~mm} \mathrm{Al,1,5} \mathrm{mm} \mathrm{Al,2}$ $\mathrm{mm} \mathrm{Al}, 2,5 \mathrm{~mm} \mathrm{Al}$, dan $3 \mathrm{~mm} \mathrm{Al}$. Pengukuran dilakukan pada 3 kondisi tegangan yaitu 55 $\mathrm{kV}, 60 \mathrm{kV}$ dan $65 \mathrm{kV}$. Dari hasil analisa pengujian keluaran pesawat sinar-x didapatkan keluaran sinar-x yang tidak sesuai tetapi masih dalam batas toleransi. Dan setelah dilakukan perhitungan nilai rata-rata dosis efektif pada pemeriksaan radiografi tulang panggul didapatkan nilai rata-rata dosis efektifnya adalah $0.069 \mathrm{mSv}$, jadi nilai rata-rata dosis efektif pada penelitian ini lebih kecil dari nilai rata-rata dosis efektif pada pemeriksaan radiografi tulang panggul diseluruh dunia berdasarkan laporan UNSCEAR 2000 yaitu $0.74 \mathrm{mSv}$.
\end{abstract}

Kata kunci : Filter Tambahan, Keluaran Sinar-X, Dosis efektif

\begin{abstract}
The measurement of General Multi Purpose X ray Machine Shimadzu has been done to know the $x$ ray quality, when using alumunium filter with the effective doses, with alumnium which has various thickness start from using no additional filter, using 0,5 $\mathrm{mm} \mathrm{Al}$, using 2,5 $\mathrm{mm} \mathrm{Al}$, and using $3 \mathrm{~mm} \mathrm{Al}$. This measurement has been done with 3 kinds of voltage which are $55 \mathrm{kV}, 60 \mathrm{kV}$ and $65 \mathrm{kV}$. This assessment gives a result that this $x$ ray machine output is not appropriate value but this value is still within the tolerance limits. And the result of the mean value assessment of the effective dose in pelvic radiography exam is 0,069 $\mathrm{mSv}$, so the mean value of the effective dose in this observation is smaller than the effective dose in pelvic radiography exam worldwide, which based on UNSCEAR 2000 report is $0,74 \mathrm{mSv}$.
\end{abstract}

Keywords : Additional Filter, X-ray Output, Effective dose.

\section{PENDAHULUAN}

Pemanfaatan pesawat sinar-X atau $X$-ray machine di bidang kesehatan terutama di bidang radiologi harus memperhatikan dua aspek, yaitu manfaat serta risiko dari penggunaannya. Tuntutan tingkat keselamatan pada penggunaan pesawat sinar-x khususnya bagi negara maju sudah menjadi suatu keharusan sebab faktor lain yang terkait dengan keselamatan radiasi antara lain kualifikasi tenaga, perancanganan ruang pesawat sinar-x, dan perlengkapan proteksi radiasi tidak menjadi masalah lagi. Bagi negara berkembang seperti Indonesia,jaminan tingkat keselamatan pada penggunaan pesawat sinar-x masih menghadapi banyak masalah, terutama dikaitkan dengan perlengkapan uji kendali mutu (Quality control test tools) yang masih terlalu mahal dan tidak dimiliki hampir di semua rumah sakit.

Beberapa faktor pada pesawat sinar-x dapat mempengaruhi keluaran (output) sinar-x dan dosis permukaan yang akan diterima oleh pasien yaitu faktor eksposi yang meliputi penggunaan $\mathrm{kV}$ dan mAs serta penggunaan filter tambahan. Variasi penggunaan filter tambahan dapat mempengaruhi besarnya keluaran purata berkas radiasi sinar-x serta dosis permukaan (dosis kulit) yang diterima pasien. Pada penggunaan filter tambahan dapat mengurangi $\pm 50 \%$ dosis permukaan yang diterima pasien[1]. Beberapa pesawat radiologi pada umumnya diperlengkapi dengan filter tambahan walaupun ada beberapa dari pesawat radiologi tersebut tidak diperlengkapi dengan filter tambahan. Namun pada penelitian ini, akan dilakukan pengujian pesawat radiologi konvensional yang dilengkapi dengan filter tambahan dan pengaruhnya terhadap dosis yang diterima pasien pada pencitraan sinar-X yang optimal. 


\section{METODE DAN BAHAN}

Penelitian tentang pengukuran dosis efektif pada pemeriksaan radiografi tulang panggul dengan menggunakan Multimeter Piranha, penelitian ini dilakukan pada Phantom tulang panggulsecara langsung.Pengukuran dosis permukaan menggunakan multimeter piranha dengan cara meletakanmultimeter $X$-ray piranha pada Phantom tulang panggul, multimeter $X$-ray piranha yang telah diekspos akan memperlihatkan nilai hasil bacaan dosis permukaan yang diterima olehobyek yang tersimpan di laptop dengan aplikasi Ortigo. Hasil bacaan dosis permukaan menggunakan multimeter $X$-ray piranha kemudian dianalisis dan dibandingkan dengan nilai rata-rata dosis efektif pada pemeriksaan radiografi tulang panggul diseluruh dunia berdasarkan laporan UNSCEAR 2000, dengan terlebih dahulu mendapatkan hasil dari multimeter $x$-ray piranha untuk mendapatkan nilai dosis permukaan pada pemeriksaan tulang panggul dan kemudian dilakukan perhitungan persamaan dosis efektif untuk mendapatkan nilai dosis efektif pemeriksaan radiografi tulang panggul.

Alat dan Bahan yang digunakan dalam penelitian ini adalah sebagai berikut :

- Pesawat Sinar-X

Dalam penelitian ini digunakan pesawat sinar-X Shimadzu General Multi Purpose X-Ray unit seperti gambar 1 dibawah ini.

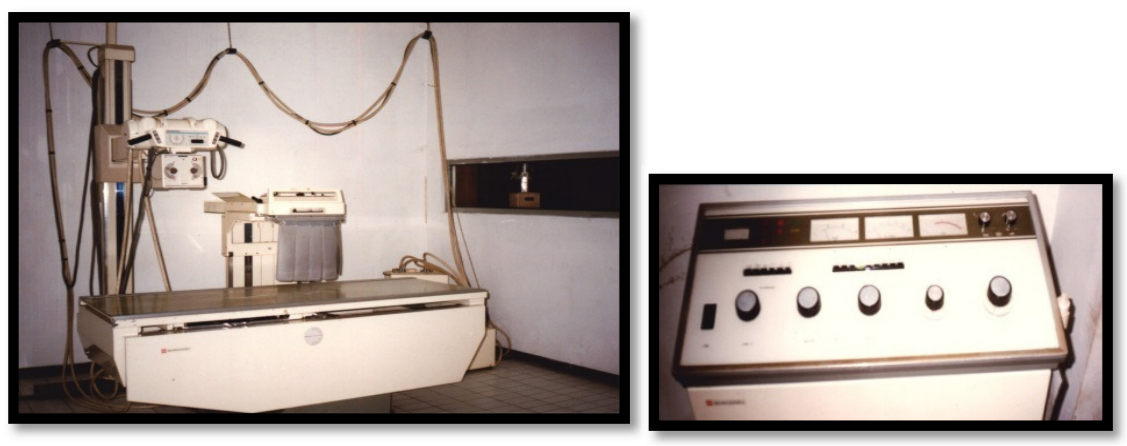

GAMBAR 1. Pesawat sinar x Shimadzu.

\section{- Phantom Radiografi Pelvis}

Merupakan Sebuah obyek yang diciptakan dengan meniru organ tubuh manusia seperti gambar 2 dibawah ini. Obyek ini dirancang dengan material yang serupa dengan organ tubuh manusia untuk keperluan medical imagine seperti mengevaluasi, menganalisa, dan pengujian kemampuan peralatan medis. Untuk keperluan proteksi radiasi maka penggunaan phantom ini sangatlah dianjurkan. Phantom pada keperluan radiologi memiliki bentuk seperti organ organ tubuh, kali ini penulis akan mengambil sample berupa phantom tulang panggul.

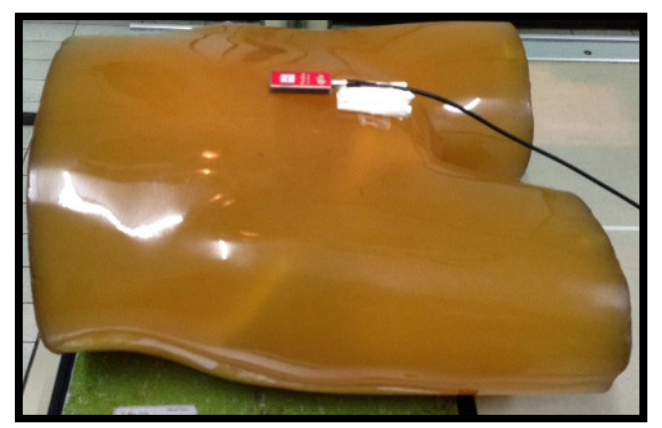

GAMBAR 2. Phantom

\section{- Multimeter X-Ray Merk "piranha"}

Multimeter piranha adalah alat yang berfungsi untuk mengukur keluaran pesawat sinar$\mathrm{X}$ (output) seperti $\mathrm{kV}, \mathrm{mA}$, second yang telah diatur pada kontrol panel. Selain itu 
multimeter piranha juga dapat digunakan sebagai alat ukur paparan radiasi (dosis), HVL, laju dosis, dan mengukur ketebalan filter.

\section{- Filter Tambahan}

Filter tambahan yang digunakan dalam penelitian ini adalah filter $0,5 \mathrm{~mm} \mathrm{Al}$, filter 1 $\mathrm{mm} \mathrm{Al}$, filter 1,5 mm Al, filter $2 \mathrm{~mm} \mathrm{Al}$, filter 2,5 $\mathrm{mm} \mathrm{Al,} 3 \mathrm{~mm} \mathrm{Al}$. Penggunaan filter tambahan berbentuk segi empat yang dapat dipasang pada dibawah kolimator, penggunaan filter tambahan ini dapat diubah-ubah sesuai dengan kebutuhan.

\section{Prosedur Penelitian}

\section{Pengujian Akurasi Keluaran Pesawat Sinar-x (kV dan s)}

Sebelum melakukan penelitian, terlebih dahulu pesawat sinar-X Shimadzu General Multi Purpose unit dicek akurasi keluarannya (output) untuk mengetahui tingkat kelayakan dari pesawat sinar-X tersebut.

\section{Pengukuran Dosis}

Setelah dilakukan pengukuran keluaran pesawat sinar-x, selanjutnya dilakukan penentuan Dosis pesawat sinar-X Shimadzu General Multi Purpose dengan menggunakan variasi filter Aluminium (Al) yaitu tanpa filter, filter $0,5 \mathrm{~mm} \mathrm{Al}$, filter $1 \mathrm{~mm} \mathrm{~mm} \mathrm{Al}$, filter $1,5 \mathrm{~mm} \mathrm{Al}$, filter $2 \mathrm{~mm} \mathrm{Al}$, filter 2,5 $\mathrm{mm} \mathrm{Al}$, dan filter $3 \mathrm{~mm} \mathrm{Al}$. Pengukuran dosis dilakukan pada tegangan $55 \mathrm{kV}, 60 \mathrm{kV}$ dan 65 $\mathrm{kV}$. Menggunakan $200 \mathrm{~mA}$ dan $700 \mathrm{~ms}$. Pengukuran dilakukan pada setiap penggunaan filter tambahan seperti gambar 3 dibawah ini.

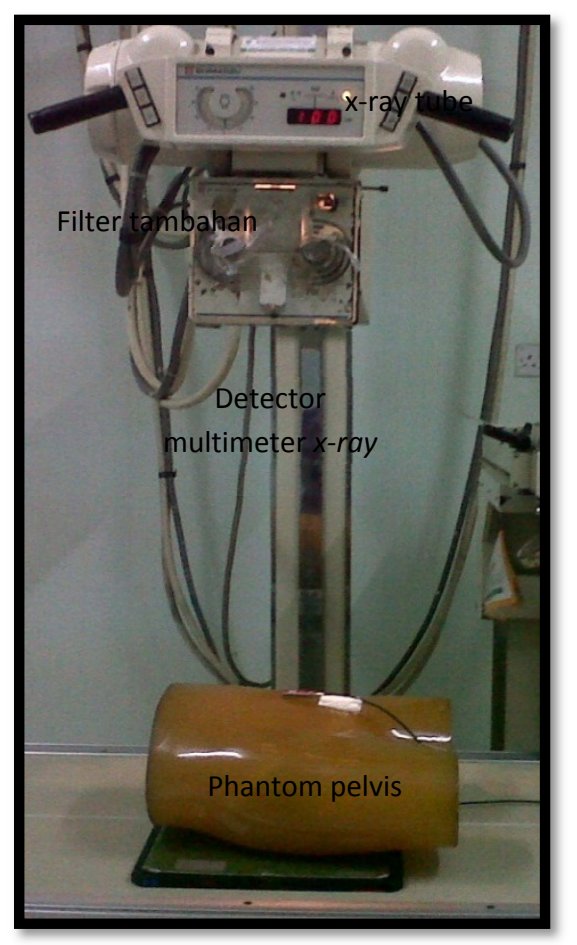

GAMBAR 3. Pengukuran dosis

Data hasil pengamatan diolah dan dianalisis dengan membandingkan pengaruh ketebalan filter aluminium (Al) pada $\mathrm{kV}$ dengan $\mathrm{mAs}$ yang sama terhadap dosis permukaan dan citra radiografi pelvis, setelah semua data penelitian didapatkan kemudian dilakukan analisa sehingga nantinya akan dapat ditarik kesimpulan hasil penelitian. Data hasil eksperimen dan perhitungan dibuat dalam bentuk tabulasi kemudian di analisis secara kuantitatif, Penelitian ini menggunakan perhitungan persamaan dosis efektif dengan terlebih dahulu mengetahui nilai hasil pengukuran dosis permukaan radiografi tulang panggul dengan menggunakan multimeter piranha. Hasil bacaan multimeter piranha dinyatakan dalam satuan dosis serap (mGy). Untuk mengetahui dosis efektif $\left(E_{T}\right)$ maka di lakukan perhitungan nilai dosis serap (mGy) diubah ke dosis efektif (mSv). 


\section{HASIL DAN PEMBAHASAN}

\section{Pengujian ketepatan tegangan tabung (kVp) sinar-X dengan menggunakan multimeter piranha.}

TABEL 1. .Data Hasil Pengujian Tegangan (Kv) Menggunakan Multimeter Piranha

\begin{tabular}{|c|c|c|c|}
\hline \multirow{2}{*}{ kVp kontrol panel } & \multicolumn{2}{|c|}{$\mathbf{2 0 0} \mathbf{~ m A ~ 0 , 0 7 ~ s}$} & Persentase penyimpangan \\
\cline { 2 - 3 } & rata-rata $\mathbf{k V}$ peak & Koreksi kV peak & 1,98 \\
\hline 45 & 44,11 & 0,89 & 2,34 \\
\hline 50 & 48,83 & 1,17 & 3,56 \\
\hline 55 & 53,04 & 1,96 & 2,42 \\
\hline 60 & 58,55 & 1,45 & 5,05 \\
\hline 65 & 61,72 & 3,28 & 6,21 \\
\hline 70 & 65,65 & 4,35 & 3,59 \\
\hline \multicolumn{3}{|c|}{ Rata-rata } \\
\hline
\end{tabular}

Dari data diatas tabel 1 dapat dilihat adanya ketidaksesuaian antara $\mathrm{kV}$ panel dengan hasil $\mathrm{kVp}$ meter sebesar $1,98 \%$ sampai dengan 6,21\% dan rata-rata penyimpangannya sebesar 3,59\%. Persamaan garis lurus yang diperoleh yaitu $\mathrm{y}=1,1464 \mathrm{x}-5,9153$.Ketidaksesuaian terkecil terjadi pada pemakaian tegangan $45 \mathrm{kV}$ sebesar 1,98\%,sedangkan penyimpangan terbesar pada pemakaian $70 \mathrm{kV}$ sebesar 6,61\%. Koefisien korelasi pada kurva diatas adalah 0,99 $(\mathrm{r}=0.99)$. Dari hasil pengukuran $\mathrm{kV}$ dapat diperoleh hasil bahwa ketidaksesuaian masih dibawah 10\%. Berdasarkan Perka BAPETEN no 8 Tahun 2011 dapat disimpulkan bahwa pesawat sinar-x Shimadzumasih layak digunakan.

\section{Pengujian ketepatan waktu eksposi (exposure time) dengan menggunakan multimeter piranha.}

Dari tabel dan gambardapat dilihat bahwa nilai waktu eksposi (s) pada multimeterpiranha masih dalam batas toleransi, tampak bahwa nilai waktu eksposi (s) pada multimeter piranha dan nilai waktu eksposi (s) pada kontrol panel tidak menunjukkan grafik yang fluktuatif, bahkan kedua nilai tersebut hampir overlapping yang menandakan bahwa fungsi circuit timer masih bekerja secara akurat.

TABEL 2. Data hasil pengujian waktu eksposi (s) menggunakan multimeter piranha

\begin{tabular}{|c|c|c|}
\hline \multirow{2}{*}{$\begin{array}{c}\text { Waktu eksposi kontrol } \\
\text { panel (s) }\end{array}$} & \multicolumn{2}{|c|}{$\mathbf{2 0 0}$ mA, 0,07 s } \\
\cline { 2 - 3 } & rata-rata bacaan second & Koreksi \\
\hline 0,02 & 0,01 & 0,01 \\
\hline 0,05 & 0,04 & 0,01 \\
\hline 0,07 & 0,06 & 0,01 \\
\hline 0,10 & 0,09 & 0,01 \\
\hline 0,20 & 0,20 & 0,00 \\
\hline 0,50 & 0,50 & 0,00 \\
\hline
\end{tabular}

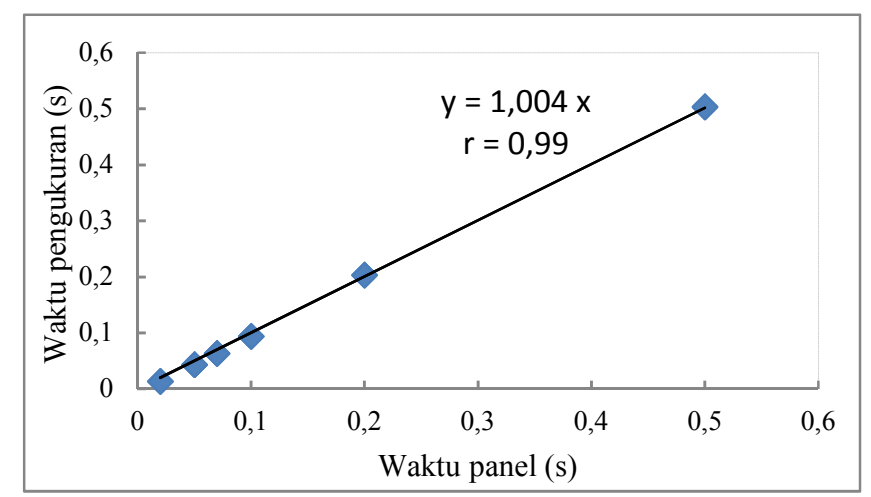

GAMBAR 4. Kurva hubungan waktu panel dengan waktu pengukuran

Tampak pada gambar 4, koefisien korelasi antara nilai waktu eksposi (s) pada multimeter piranha dan nilai waktu eksposi pada kontrol panel memperlihatkan nilai $r=0.99$ yang berarti 
bahwa hubungan keduanya sangat kuat. Tidak ada perbedaan yang signifikan antara waktu pada panel dengan waktu pada pengukuran. Hal ini menunjukkan bahwa waktu penyinaran pesawat sinar-x Shimadzustabil. Persamaan garis lurus yang diperoleh $\mathrm{y}=1,004 \mathrm{x}$. Berdasarkan Perka BAPETEN no 8 Tahun 2011, toleransi waktu penyinaran untuk pesawat sinar-X radiodiagnostik konvensional adalah $\pm 10 \%+0,01 \mathrm{~s}$ sehingga dapat disimpulkan ketidaksesuaian waktu penyinaran pada pesawat Shimadzumasih dalam batas tolereansi. Hasil uji pengaruh ketebalan filter Aluminium (Al) pada variasi $\mathrm{kV}$ dengan mAs yang
sama terhadap Dosis Permukaan

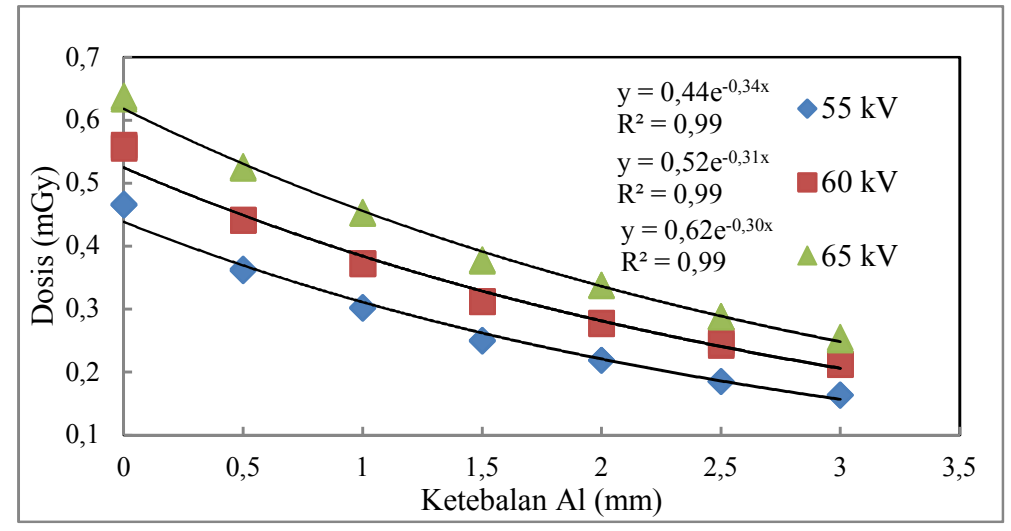

GAMBAR 5. Grafik penambahan filter Aluminium terhadap Dosis pada kondisi $55 \mathrm{kV}, 60 \mathrm{kV}, 65 \mathrm{kV}$ dengan $200 \mathrm{~mA}$, $0,07 \mathrm{~s}$

Dari gambar grafik gambar 5 diatas menunjukan dosis paparan dibandingkan ketebalan filter aluminium yang digunakan, apabila ditarik garis horizontal dapat terlihat penurunan dosis sekitar $50 \%$ untuk kondisi faktor eksposi $65 \mathrm{kV}, 200 \mathrm{~mA}, 0,07 \mathrm{~s}$ dari mula-mula 0,64 mGy menjadi $0,34 \mathrm{mGy}$,Pada faktor eksposi $60 \mathrm{kV}, 200 \mathrm{~mA}, 0,07 \mathrm{~s}$ yang mula-mula $0,56 \mathrm{mGy}$ menjadi $0,28 \mathrm{mGy}$, dan pada faktor eksposi 55, $200 \mathrm{~mA}, 0,07 \mathrm{~s}$ yang mula-mula0,47 mGy menjadi 0,22 mGy rata-rata ada pada penggunaan ketebalan filter Al sekitar $2 \mathrm{~mm}$ Al.penggunaan filter ini bertujuan untuk menyerap radiasi rendah yang tidak akan mampu menembus obyek/ pasien dalam menghasilkan citra radiografi. Radiasi yang berenergi rendah ini hanya akan meningkatkan dosis yang diterima oleh pasien. Penurunan dosis terjadi secara eksponensial dengan bertambahnya ketebalan filter dengan nilai koefisien korelasi diatas 0,99.

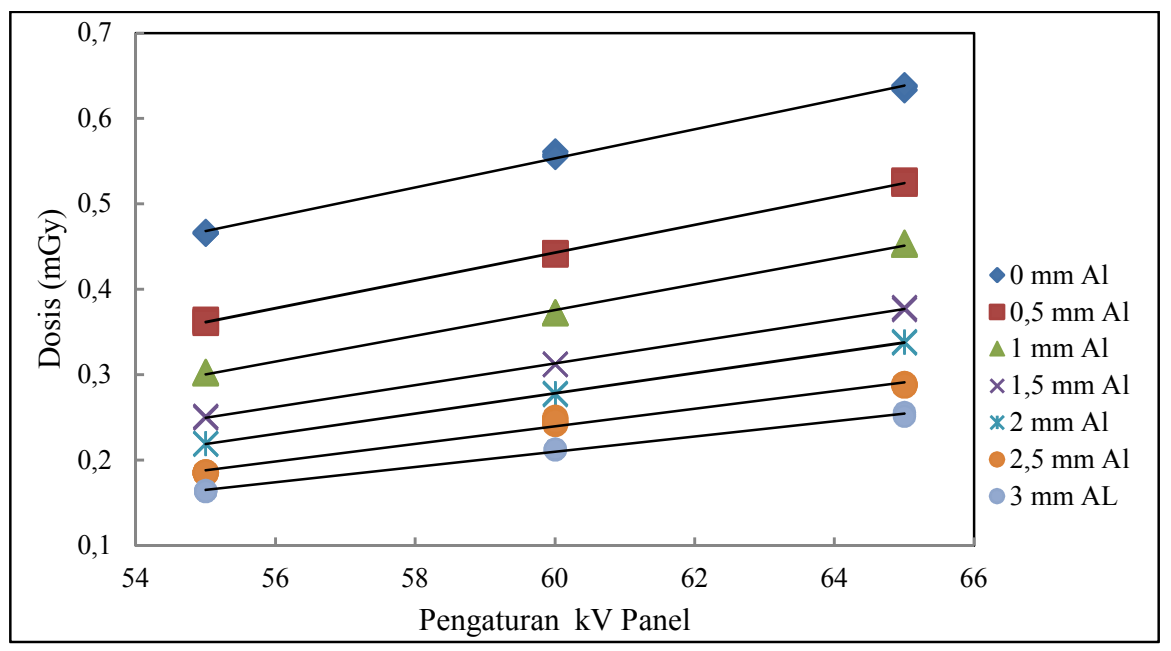

GAMBAR 6. Grafik dosis pada setingan $\mathrm{kV}$ dengan vasiasi ketebalan filter.

Pada gambar 6 menunjukkan pengaruh penambahan fiterAluminium dalam penurunan dosis yang diterima dengan kondisi faktor eksposi yang sama. Semakin tinggi ketebalan filter Aluminium (Al) yang digunakan maka semakin kecil dosis paparan yang diterima. Setelah 
mendapatkan nilai dosis permukaan menggunakan multimeter piranha, Kemudian untuk mengetahui dosis efektif maka dilakukan perhitungan menggunakan persamaan dosis efektif. Dalam mempermudah, makanilaidosis efektif dibulatkan. Nilai dosis efektif dapat dilihat pada tabel 3 berikut ini :

TABEL 3. Nilai dosis efektif pada pemeriksaan radiografi tulang panggul

\begin{tabular}{|c|c|c|c|c|c|}
\hline Gambar & $\begin{array}{c}\mathrm{kV} \text { yang } \\
\text { digunakan }\end{array}$ & $\begin{array}{l}\text { Ketebalan Filter } \\
\quad(\text { mm Al) }\end{array}$ & $\begin{array}{c}\text { Dosis } \\
\text { permukaan } \\
(\mathrm{mGy})\end{array}$ & $\begin{array}{l}\mathbf{W}_{T} \\
\quad(\mathrm{mSv})\end{array}$ & $\begin{array}{c}\text { Dosis } \\
\text { efektif } \\
(\mathrm{mSv})\end{array}$ \\
\hline 1 & \multirow{7}{*}{55} & $\begin{array}{l}\text { Tanpa filter } \\
\text { tambahan }\end{array}$ & 0,47 & 0,20 & 0,09 \\
\hline 2 & & 0,50 & 0,36 & 0,20 & 0,07 \\
\hline 3 & & 1,00 & 0,3 & 0,20 & 0,06 \\
\hline 4 & & 1,50 & 0,25 & 0,20 & 0,05 \\
\hline 5 & & 2,00 & 0,22 & 0,20 & 0,04 \\
\hline 6 & & 2,50 & 0,19 & 0,20 & 0,04 \\
\hline 7 & & 3,00 & 0,16 & 0,20 & 0,03 \\
\hline 8 & \multirow{7}{*}{60} & $\begin{array}{l}\text { Tanpa filter } \\
\text { tambahan }\end{array}$ & 0,56 & 0,20 & 0,11 \\
\hline 9 & & 0,50 & 0,44 & 0,20 & 0,09 \\
\hline 10 & & 1,00 & 0,37 & 0,20 & 0,07 \\
\hline 11 & & 1,50 & 0,31 & 0,20 & 0,06 \\
\hline 12 & & 2,00 & 0,28 & 0,20 & 0,06 \\
\hline 13 & & 2,50 & 0,25 & 0,20 & 0,05 \\
\hline 14 & & 3,00 & 0,21 & 0,20 & 0,04 \\
\hline 15 & \multirow{7}{*}{65} & $\begin{array}{l}\text { Tanpa filter } \\
\text { tambahan }\end{array}$ & 0,64 & 0,20 & 0,13 \\
\hline 16 & & 0,50 & 0,53 & 0,20 & 0,11 \\
\hline 17 & & 1,00 & 0,45 & 0,20 & 0,09 \\
\hline 18 & & 1,50 & 0,38 & 0,20 & 0,08 \\
\hline 19 & & 2,00 & 0,34 & 0,20 & 0,07 \\
\hline 20 & & 2,50 & 0,29 & 0,20 & 0,06 \\
\hline 21 & & 3,00 & 0,25 & 0,20 & 0,05 \\
\hline \multicolumn{5}{|c|}{ Nilai rata-rata dosis efektif } & 0,069 \\
\hline
\end{tabular}

Setelah dilakukan perhitungan nilai rata-rata dosis efektif pada pemeriksaan radiografi tulang panggul didapatkan nilai rata-rata dosis efektifnya adalah $0.069 \mathrm{mSv}$, jadi nilai rata-rata dosis efektif pada penelitian ini lebih kecil dari nilai rata-rata dosis efektif pada pemeriksaan radiografi tulang pangguldiseluruh dunia berdasarkan laporan UNSCEAR 2000 yaitu $0.74 \mathrm{mSv}$.

\section{KESIMPULAN}

Berdasarkan data dan analisa yang dilakukan pada penelitian ini maka dapat diambil beberapa kesimpulan yaitu Adanya ketidaksesuaian tegangan dan waktu penyinaran yang diatur pada kontrol panel dengan tegangan dan waktu penyinaran yang dihasilkan dari pesawat sinar-X. Ketidaksesuaian pada pesawat sinar-x ini masih dalam batas toleransi sehingga masih layak untuk digunakan. Pemakaian filter tambahan tidak mempengaruhi tegangan puncak $(\mathrm{kVp})$ pesawat. Tegangan puncak $(\mathrm{kVp})$ yang digunakan akan sama sebelum maupun setelah menembus filter tambahan. Penurunan dosis terjadi secara eksponensial dengan bertambahnya ketebalan filter dengan nilai koefisien korelasi diatas 0,99 Didapatkan nilai rata-rata dosis efektifnya adalah $0.069 \mathrm{mSv}$, jadi nilai rata-rata dosis efektif pada penelitian ini lebih kecil dari nilai rata-rata dosis efektif pada pemeriksaan radiografi tulang pangguldiseluruh dunia berdasarkan laporan UNSCEAR 2000 yaitu $0.74 \mathrm{mSv}$.

\section{DAFTAR PUSTAKA}

[1] Curry, T. s., Dowdey, J. E., \& Murry, R. C. (1990). Christensen's Physics of Diagnostic Radiology, fourth edition. USA: Lea \& Febiger. 
[2] Bushberg, J. T., Seibert, J. A., Leidholdt, E. M., \& Boone, J. M. (2002). The Essential Physics of Medical Imaging, second edition. Philadelphia: Lippincott Williams \& Wilkins.

[3] Dendy, P.P., \& Heaton, B. (1999). Physics for Diagnostic Radiology. USA: Institute Of Physycs Publishing.

[4] Van Der Plaats, G. (1969). Medical X-Ray Technique. London and Basingstoke: The Macmillan Press Ltd.

[5] Carlton, R. R. (1992). Principles of Radiographic Imaging. New York: Delmar Publishers Inc.

[6] Rasad, S. (2005). Radiologi Diagnostik. Jakarta: Gaya Baru

[7] Meredith, W. J., \& Massey, J. B. (1972). Fundamental Physics of Radiology, second edition. Bristol: John Wright \& Sons Ltd.

[8] Akhadi, M. (2000). Dasar-dasar Proteksi Radiasi. Jakarta: PT Rineka Cipta Jaksa.

[9] Report United National Scientific Committe on the Effects of Ionizing Radiation (UNSCEAR) 2000

[10] Peraturan Kepala BAPETEN No 8 Tahun 2011 Tentang Keselamatan Radiasi dalam Denggunaan Pesawat Sinar-x Radiologi Diagnostik dan Intervensional.

[11] Mrs M. J. Harvey, Assurance of Quality in the Diagnostik X-ray Departement, The British Institute of Radiology, London, 1988 